\title{
Skin barrier integrity is enhanced after topical application of emulsions with an acidic $\mathrm{pH}$ \\ E. Proksch ${ }^{1}$, S. Merker², C. Neumann ${ }^{1}$, A. Kilic ${ }^{2}$, C. Abels ${ }^{2}$ \\ ${ }^{1}$ Department of Dermatology, University of Kiel, Kiel and ${ }^{2} \mathrm{Dr}$. August Wolff GmbH \& Co. KG, Arzneimittel, Bielefeld, Germany
}

\section{Introduction and Methods}

The $\mathrm{pH}$ of the stratum corneum is slightly acidic (mean 4.9) and tightly regulated. This is important for antimicrobial defense and the formation of the physical barrier. The acidic $\mathrm{pH}$ inhibits the growth of pathogenic Staphylococcus aureus and enables optimal work of enzymes for lipid synthesis, epidermal differentiation and desquamation.

Here we asked whether topical application of an oil- in- water $(O / W)$ emulsions adjusted to $\mathrm{pH} 4$ in comparison to $\mathrm{pH} 5.8$ and the untreated control influences biophysical markers and mechanical stability of the skin barrier, stratum corneum morphology and inflammation.

Twenty-four healthy volunteers aged 18 to 75 years were treated randomized on the lower arms for 30 days; $\mathrm{pH}$, TEWL, SC hydration, mechanical stability, corneocyte size and inflammation were measured. On day 30 , skin was tape-stripped by D-Squame ${ }^{\circledR}$ strips until a threefold increase in TEWL occurred. Thereafter, the emulsions were applied once more; $\mathrm{pH}$ was recorded 3,6 and 24 hours later (day 31 ).

\section{Results}

pH and TEWL after treatment with emulsions adjusted to $\mathrm{pH} 4$ or $\mathrm{pH} 5.8$ Application of the $\mathrm{pH} 4$ emulsion resulted in a significant decrease in $\mathrm{pH}$ at day 30 as well as 3 and 6 hours later and after the last treatment. In contrast, $\mathrm{pH}$ was significantly increased after application of the $\mathrm{pH} 5.8$ emulsion at these time points. $\mathrm{pH}$ was always lower after application of the $\mathrm{pH} 4$ compared to the $\mathrm{pH} 5.8$ emulsion.

TEWL was slightly reduced by both emulsions on day 30 compared to day 1.24 hours after the last application of the emulsions (day 31), it was slightly reduced by both emulsions compared with untreated area. This shows, that both emulsions slightly reduced the skin's water loss.

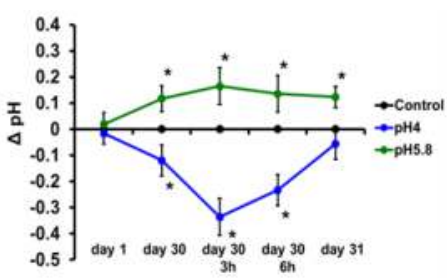

pH

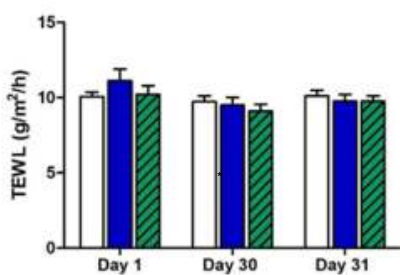

TEWL

SC hydration and number of tape-strips to achieve a threefold increase in TEWL after application of $\mathrm{pH} 4$ and $\mathrm{pH} 5.8$ emulsions

SC hydration was determined at day 1 and at day 30 . Treatment with both emulsions, $\mathrm{pH} 4$ and $\mathrm{pH} 5.8$, resulted in a similar, significant increase in hydration $(n=24, p<0.05)$.

The number of D-Squame ${ }^{\circledR}$ strips, needed to increase TEWL 3-fold, was significantly increased compared to control after both treatment, but more after application of the $\mathrm{pH} 4$ emulsion, showing enhanced mechanical SC stability $(n=24, p<0.05)$.

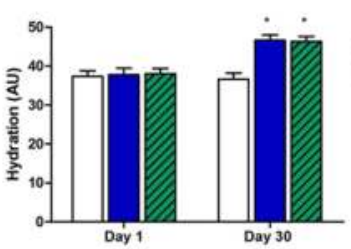

SC hydration
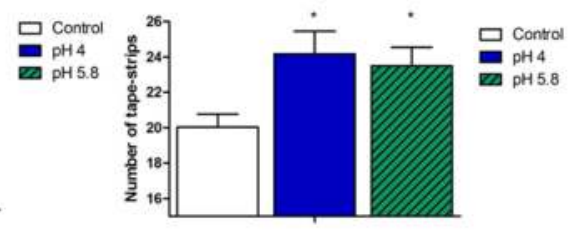

number of tape-strips
Increase in erythema and IL-1a protein content after tape-stripping and application of the $\mathrm{pH} 4$ and $\mathrm{pH} 5.8$ emulsions

The increase in erythema as a sign of inflammation, determined 2 hours after tapestripping, was slightly lower after treatment with $\mathrm{pH} 4$ compared to treatment with $\mathrm{pH} .5 .8$ emulsion and the untreated control (N.S.).

IL-1 a ELISA protein, examined in D-Squames ${ }^{\circledR}$, was significantly reduced by both treatments but more by the $\mathrm{pH} 4$ emulsion $(n=24, p<0.05)$.

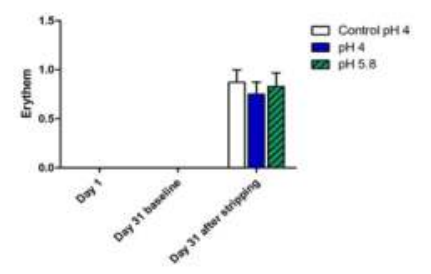

erythema

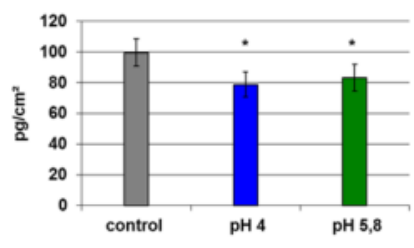

IL-1 $\alpha$ protein content
Corneocyte structure and size after treatment with the emulsions adjusted to $\mathrm{pH} 4$ and $\mathrm{pH} 5.8$

Fluorescent microscopy pictures of corneocytes stained by Nile red showed intact corneocytes after the treatments. Corneocyte size was increased by both emulsions; significant increase compared to untreated was achieved by the $\mathrm{pH} 4$ emulsion, only. The increase achieved by the $\mathrm{pH} 4$ compared to $\mathrm{pH} 5.8$ emulsion was also significant $(n=24, p<0.05)$.

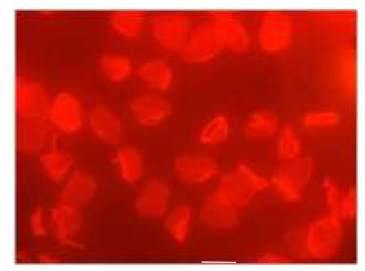

representative corneocytes structure

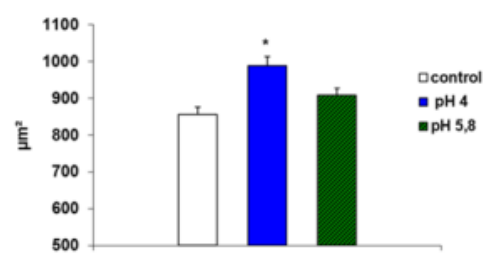

corneocyte size

\section{Summary}

- After 4 weeks of treatment $\mathrm{pH}$ was significantly reduced by the $\mathrm{pH} 4$ emulsion only.

- SC hydration was significantly increased by both preparations.

- The number to D-Squame ${ }^{\circledR}$ strips to achieve a threefold increase in TEWL was significantly enhanced by both treatments, slightly more by pH 4.

- Inflammation determined by erythema was slightly reduced and IL-1 a protein amount was significantly reduced by both treatments, but more by the $\mathrm{pH} 4$ emulsion.

- Corneocyte size was significantly increased by the pH 4 emulsion.

\section{Conclusion}

Treatment with a pH 4 O/W emulsion reduced skin SC $\mathrm{pH}, \mathrm{TEWL}$ and inflammation and increased SC hydration, corneocyte size, and stability against mechanical irritation. This is important for all diseases with a disrupted skin barrier and inflammation, especially for the eczema group. 